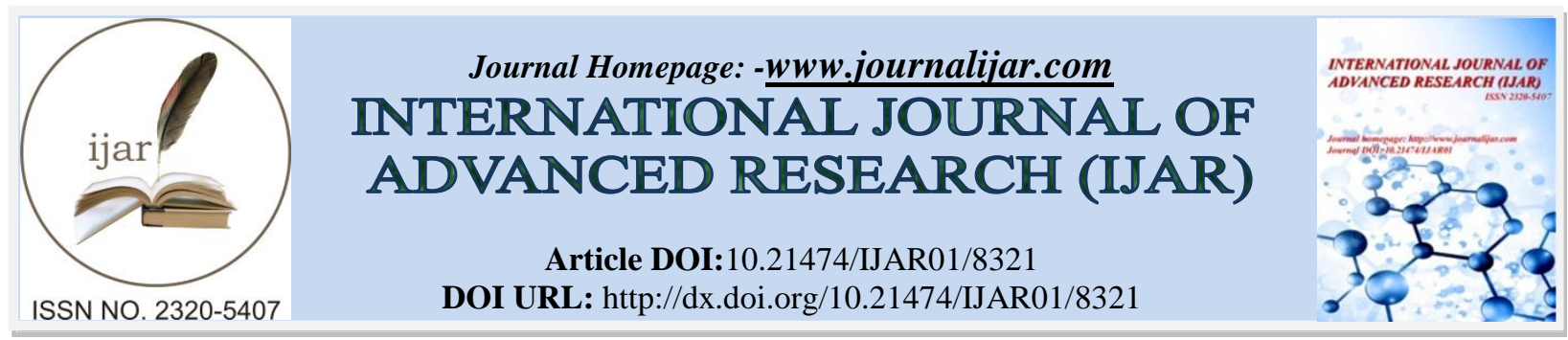

RESEARCH ARTICLE

\title{
EFFECT OF INDUCED FIPRONIL TOXICITY ON HUMORAL IMMUNE RESPONSE IN WHITE LEGHORN COCKERELS.
}

Dheeraj Adhikari ${ }^{1}$ and Seema Agarwal ${ }^{2}$.

1. M.V.Sc. Student, Department of Pathology, College of Veterinary \& Animal Sciences, G.B. Pant University of Agriculture and Technology, Pantnagar-263 145, Udham Singh Nagar (Uttarakhand) INDIA.

2. Associate Professor, Department of Pathology, College of Veterinary \& Animal Sciences, G.B. Pant University of Agriculture and Technology, Pantnagar-263 145, Udham Singh Nagar (Uttarakhand) INDIA.

\section{Manuscript Info}

Manuscript History

Received: 04 November 2018

Final Accepted: 06 December 2018

Published: January 2019

Key words:-

Insecticides, Humoral Immune Response, Fipronil, White Leghorn Cockerels.

\section{Abstract}

Pesticide use in the modern agriculture, animal husbandry and public health practices has increased enormously. They are nearly ubiquitous in environment causing deleterious effects on the health of man and animal, which results in substantial economic losses. Fipronil was placed in the market in 1993; it is the member of a new and relatively small class of pesticides, the phenyl pyrazoles. Limited investigations have been carried on effect of fipronil in health of animals and man. Therefore, present study was designed to study the effect of fipronil toxicity on humoral immune response in white leghorn cockerels. Twenty white leghorn male chickens were procured and kept in deep litter system under standard conditions. They were randomly divided into four groups of 5 birds each. After one week of adaptation period, different doses of Fipronil were administered orally through feed at 1,5 and 10 p.p.m. levels to groups G1, G2 and G3 respectively, daily for 100 days. Every 20 days, blood was taken from each bird and serum was separated to estimate serum gamma globulin level. Specific humoral immune response was measured by performing Lymphocyte Stimulation Test using LPS as mitogen at $100^{\text {th }}$ day. There was significant reduction in gamma globulin level between group G1, G2 and G3 after 40 days. There was significant $(\mathrm{P}<0.05)$ decrease in the delta OD in LPS stimulated cells in all treated groups as compared to control, after 100 day of trial indicating immunosuppressive effect of the pesticide.

Copy Right, IJAR, 2017,. All rights reserved.

\section{Introduction:-}

Poultry industry contributes a major share in terms of protein supplement through meat and eggs in human food. According to (2009-2010) poultry industry has emerged as the most dynamic and fastest expanding segment in animal husbandry sector with 47.4 billion eggs produced by 2.4 billion layers and 3 billion broilers giving 2.25 million metric tons of poultry meat and likely to grow up to 75.6 billion eggs and 5.21 million metric tons of poultry meat by year 2012. According to (Kumar, 2008) value of output from poultry sector is nearly 300 billion rupees and the sector provides direct or indirect employment to over 5 million people. The livestock sector and poultry sector

Corresponding Author:- Dr. Seema Agarwal.

Address:- Associate professor, Department of Pathology, College of Veterinary \& Animal Sciences, G.B. Pant University of Agriculture and Technology, Pantnagar-263 145, Udham Singh Nagar 
contributes approximately $4 \%$ and $9 \%$ respectively to country's GDP where as $27 \%$ contribution to agriculture GDP is from livestock sector and poultry sector.

So, to meet the increased demands of the ever increasing population, pesticide use in the modern agriculture, animal husbandry and public health practices has increased enormously. Pesticides affect man, environment and wild life including birds. According to (Chauhan, et al., 2006) 90,000 MT of technical grade pesticides are used annually to control pests and plant diseases in India. The pesticides are classified as insecticides, fungicides, weedicides, herbicides, nematodicides and rodenticides; of which insecticides constitutes $77 \%$ of the total pesticides used in different agricultural and animal husbandry practices and in public health operations. About $50 \%$ of food commodities are contaminated with pesticide residues in India. Livestock and poultry are frequently exposed to pesticide, drugs and environmental contaminants. Through contaminated feed, water, or air insecticides are ingested and absorbed in systemic circulation. They are metabolised and excreted through the animal body. However, some of the residue which remains inside the body gets deposited in various body tissues and is responsible for deleterious effect on various body organs. Pesticides are present in air, soil and water which leave their residue in food chain (Ram, et al., 1987) (Kaushik, et al., 1991) causing adverse effect on the health status of man and animals including poultry.

Fipronil was discovered and developed by Rhone-Poulenc between 1985-1987 and placed in the market in 1993. It is the member of new and relatively small class of pesticides, the phenyl pyrazoles, which are principally chemicals with a herbicidal effect (Rhone-Poulnec, 1996). Chemically, it is a (5-amino-1-[2, 6-dichloro-4-(trifluoromethyl) phenyl]-4[trifluoromethyl) sulfinyl]-1H-pyrzole). It was registered as a pesticide in the United States in 1996 (Bobe, 1998). Fipronil or its metabolite noncompetitively inhibits GABA-induced ion influx by targeting the GABA-regulated chloride channels in insects (Cole, et al., 1993). Fipronil binding blocks the inhibitory action of GABA, leading to hyperexcitation, and in appropriate concentrations even death (Bobe, 1998). Fipronil exhibits $>500$-fold selective toxicity to insects over mammals mainly because of differences in affinity of receptor binding between insect and mammalian receptor (Cole, et al., 1993) (Hainzl, et al., 1998) (Grant, et al., 1990) (Kamijima, et al., 2000) (Zhao, et al., 2005). Fipronil binds more tightly to the $\mathrm{GABA}_{\mathrm{A}}$ receptor in insects than mammals.

Fipronil is sold commercially under various trade names including Icon, Regent, Ascend, Termidor, Goliath, Chipko, Chipko Choice and Adonis for agriculture use. It is available in a wide range of formulations including dispersible granule (WG), micro granule (GR), flowable solid (FS), soluble concentrate (SC) and ultra low volume (ULV). It is also sold as a veterinary product for tick, mite and flea control on pet and domestic stock under the trade names Frontline and Top spot (Rhone-Poulnec, 1996)

Fipronil is classified as a WHO Class II moderately hazardous pesticide. The U.S. EPA classified Fipronil as "Group C possible human carcinogen," based on "increase in thyroid follicular cell tumours in both sexes of the rat". There was no report regarding effect of Fipronil on the white leghorn chicken involving serum biochemical parameters. Therefore, present investigation was planned to study the effect of fipronil at different dose rate on humoral immune response in white leghorn chickens.

\section{Materials And Methods:-}

Twenty white leg horn male chickens of one month age, weighing about 150 to 200 gms were procured and kept at Instructional Poultry Farm Nagla, Pantnagar. The birds in poultry shed in deep litter system under standard management conditions and were randomly divided into four groups of 5 birds each. After one week of adaptation period, different doses of Fipronil were administered orally through feed at 1, 5 and 10 p.p.m. levels to groups G1, G2 and G3 respectively, daily for 100 days. The birds of group "C" served as control. Blood samples were collected from wing vein in sterilized disposable syringes (22 gauge needles) after proper restraining of birds. Blood samples were transferred in non heparin coated tubes for serum separation. Collection of blood samples was done at the 20 days interval starting from day 0 during 100 days study. Approximately, $5 \mathrm{ml}$ of blood per bird was collected.

After collection, blood was allowed to clot in non heparin coated test tubes kept in slanting position (to provide larger surface area) for 3-4 $\mathrm{hr}$ at room temperature $\left(18-20^{\circ} \mathrm{C}\right)$. After clotting of blood, the serum oozed out of the retracted clot and was collected with the help of micropipette in clean micro centrifuge tube which were then centrifuged at $4^{0} \mathrm{C}$ for 20 minutes at $4000 \mathrm{rpm}$ in a refrigerated centrifuge. The top layer of serum was collected in another clean micro centrifuge tube with the help of micropipette and stored at $-20^{\circ} \mathrm{C}$ in deep freezer. 
The serum $\gamma$-globulins were estimated following the modified Friedman's method as described by (Oser, 1976). The $\gamma$-globulins were precipitated by using ammonium sulphate-sodium chloride solution in which $0.3 \mathrm{ml}$ of clear serum was overlayed over $5.7 \mathrm{ml}$ ammonium sulphate-sodium chloride solution. It was gently mixed and kept in ice bath for 15 minute and then centrifuged at 1200xg for 10 minute. The precipitates thus obtained were dissolved in $0.2 \mathrm{ml}$ of normal saline solution (NSS) and process of precipitation was repeated again using ammonium sulphate-sodium chloride solution. Finally the precipitates were dissolved in $2 \mathrm{ml} \mathrm{NSS}$, to this $5 \mathrm{ml}$ of biuret reagent was added and kept at room temperature for 10 minute. The optical density was read at $555 \mathrm{~nm}$ in blood auto analyzer by setting zero with blank (a mixture of $2 \mathrm{ml}$ NSS and $5 \mathrm{ml}$ biuret reagent).

The evaluation of the activity of B lymphocytes was carried out by the method as explained by (Rai-el-Balhaa, et al., 1987) with minor modifications as proposed by (Chauhan, 1995).

\section{Mitogen:-}

Lipopolysaccharide (LPS) was used as mitogen for B-cell blastogenesis. LPS were dissolved in RPMI-1640 cell culture media in a concentration of $4 \mu \mathrm{g} / \mathrm{ml}$ to be used for stimulation of cells respectively.

\section{Cell Culture Medium:-}

One vial of RPMI-1640 (Hi-media, India) was dissolved in $900 \mathrm{ml}$ of sterilized triple glass distilled water at room temperature. The $\mathrm{pH}$ of the media was adjusted to $7.2 \pm 0.1$ by adding $2 \% \mathrm{NaHCO}_{3}$. The final volume was then made to 1 liter with the help of sterilized triple glass distilled water. To the media, penicillin (100 IU/ml) and streptomycin $(100 \mu \mathrm{g} / \mathrm{ml})$ were added before sterilization by passing through Seitz grade glass filter under positive pressure to prevent the rise of $\mathrm{pH}$. This sterilized media was then transferred into $100 \mathrm{ml}$ conical flasks and stored at $4^{0} \mathrm{C}$ till further use.

\section{Separation of lymphocytes:-}

Three $\mathrm{ml}$ of blood was collected in fresh, sterilized, disposable syringe heparinised with heparin (125 IU/ml). The collected blood was diluted with equal volume of RPMI-1640 media. This mixture was then layered carefully over 3 $\mathrm{ml}$ of histopaque (Sigma, cat. no-1077) so as to avoid mixing of the blood and histopaque. Then the test tubes were centrifuged in a swing type centrifuge at $400 \mathrm{~g}$ for 30 minutes. The mixture was separated in three layers, a lower compact layer of RBC, an upper layer of serum and histopaque and a middle layer of lymphocytes. This middle buffy layer was carefully aspirated with the help of sterilized Pasteur pipette. This layer was further washed with RPMI-1640 twice, and cell viability was examined using trypan blue dye exclusion test (Boyse, et al., 1964). The final concentration of the cells was adjusted to be $1 \times 10^{7}$ cells per ml of RPMI-1640 medium. To the final cell suspension $10 \%$ foetal calf serum was added.

\section{Test procedure:-}

For the estimation of lymphocyte blastogenesis, 96 well, flat bottom tissue culture plates (Cellstar, Grenier bio-one) were used. Each sample was used in triplicate whose average was used as the final reading for the given sample. Each sample had its own control, also in triplicate for comparison. For the triplicate wells, $100 \mu \mathrm{l}$ of cell suspension, $50 \mu \mathrm{l}$ of media and $50 \mu \mathrm{l}$ of LPS $(4 \mu \mathrm{g} / \mathrm{ml})$ as mitogen were added. For blank $100 \mu \mathrm{l}$ of media alone was used.

Statistical difference between respective means for various parameters was evaluated using appropriate statistical tests. Comparisons among the treatment groups were made. Statistical analysis of the data was done using ANOVA technique according to the method described by (Snedecor, et al., 1989). Statistically significant difference was considered at 5\% level. After loading, the plates were sealed with parafilm (Pechiney plastic packaging) and were incubated at $37^{\circ} \mathrm{C}$ for 72 hours in $\mathrm{CO}_{2}$ incubator (Forma Scientific) with $5 \% \mathrm{CO}_{2}$ pressure. Four hours before the completion of the incubation period, $50 \mu \mathrm{l}$ of MTT ( $4 \mathrm{mg} / \mathrm{ml}$, Sigma) was added to each of the well (Rai-el-Balhaa, et al., 1987). It was again incubated for four hours. After the completion of 72 hours of incubation, $100 \mu l$ of isopropyl alcohol was added to each well to stop the reaction of cells with MTT. The plate was then subjected to ELISA plate reader to read the optical density (OD) at $570 \mathrm{~nm}$. Triplicate sample wells were averaged to get the final OD of a sample wells. Average of the control wells was taken as the final OD of control wells. The difference of the sample and control wells was expressed as the final reading in terms of $\Delta \mathrm{OD}$. 


\section{Result:-}

The results of mean $\gamma$-globulin values from different groups are presented in Table 1 and Graph 1 . There was a significant $(\mathrm{P}<0.05)$ decrease in group $\mathrm{G} 1, \mathrm{G} 2$ and G3 as compared to the control after $20^{\text {th }}$ days of feeding till the end of study. Significant reduction was noticed in between group G1, G2 and G3 after 40 days onward till the end of study.

The results of LST values from different groups are presented in Table 2 and Graph 2. There was significant $(\mathrm{P}<0.05)$ decrease in the delta OD in all LPS and Con-A treated group as compared to control after 100 day of trial.

The cell mediated response was assessed in birds treated with insecticide using lymphocyte stimulation test as per the method of (Rai-el-Balhaa, et al., 1987) employing MTT assay. Birds immunized with NCDV vaccine and expose to different doses of insecticide showed marked decrease in the delta OD after stimulation with Con-A that indicate lowered cellular immune response. There was significant $(\mathrm{P}<0.05)$ decrease in the delta OD in all LPS and Con-A treated group as compared to control on $100^{\text {th }}$ day of study. Decrease in the lymphocyte proliferation with Con-A is an indication of suppression of T-cell blastogenesis which are essential for mounting of both cell mediated and humoral immune response. Also there was significant decrease in the delta OD after stimulation with LPS that indicate lowered B-cell blastogenesis.

Table 1:-Mean $\gamma$-globulin concentration (gm/dl) of RBCs in different groups of experimental birds (mean \pm S.E).

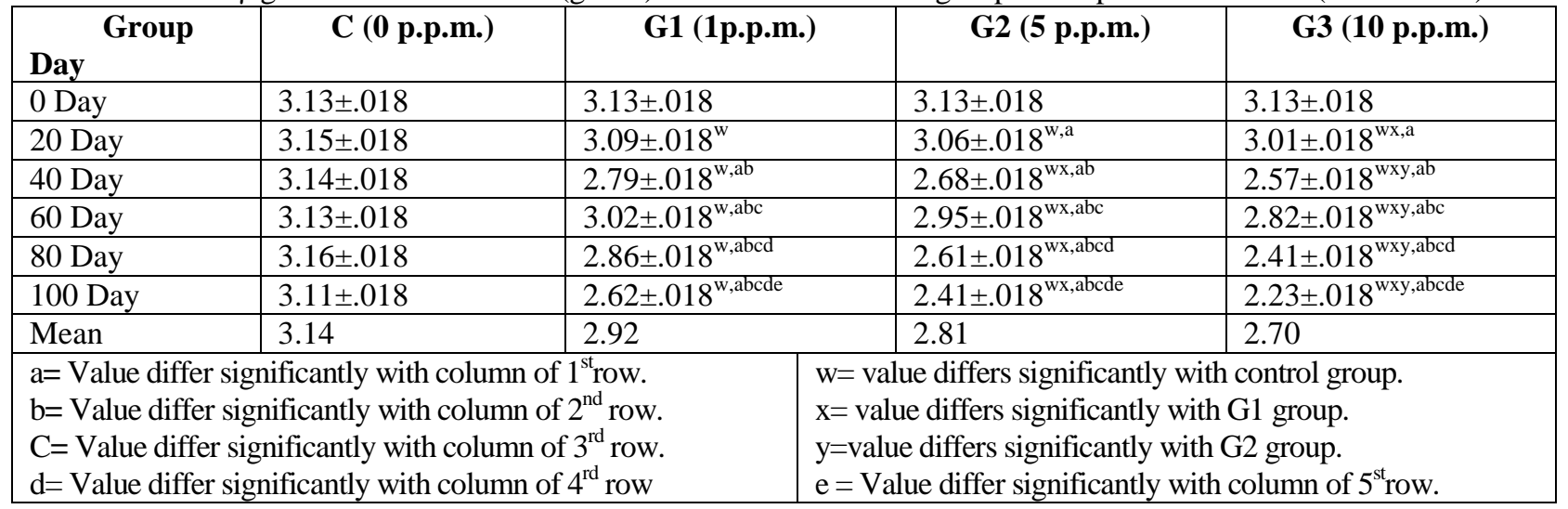

Table 2:-Mean optical density of LST in different groups of experimental birds (mean \pm S.E).

\begin{tabular}{|l|l|l|l|l|}
\hline $\begin{array}{c}\text { Group } \\
\text { Mutagen }\end{array}$ & C (0 p.p.m.) & G1 (1p.p.m.) & G2 (5 p.p.m.) & G3 (10 p.p.m.) \\
\hline LPS & $0.686 \pm .004$ & $0.465 \pm .004^{\mathrm{w}}$ & $0.413 \pm .004^{\mathrm{wx}}$ & $0.383 \pm .004^{\mathrm{wxy}}$ \\
\hline
\end{tabular}

$\mathrm{W}=$ value differs significantly with control group.

$\mathrm{x}=$ value differs significantly with G1 group.

$\mathrm{y}=$ value differs significantly with $\mathrm{G} 2$ group. 


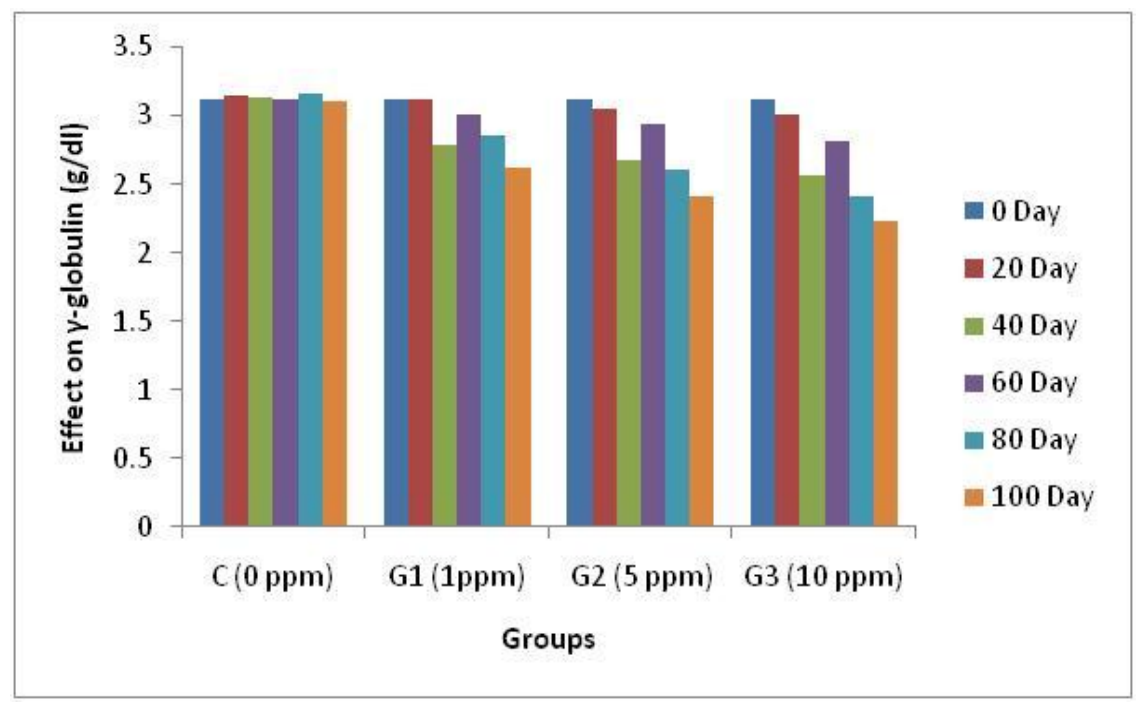

Graph 1:-

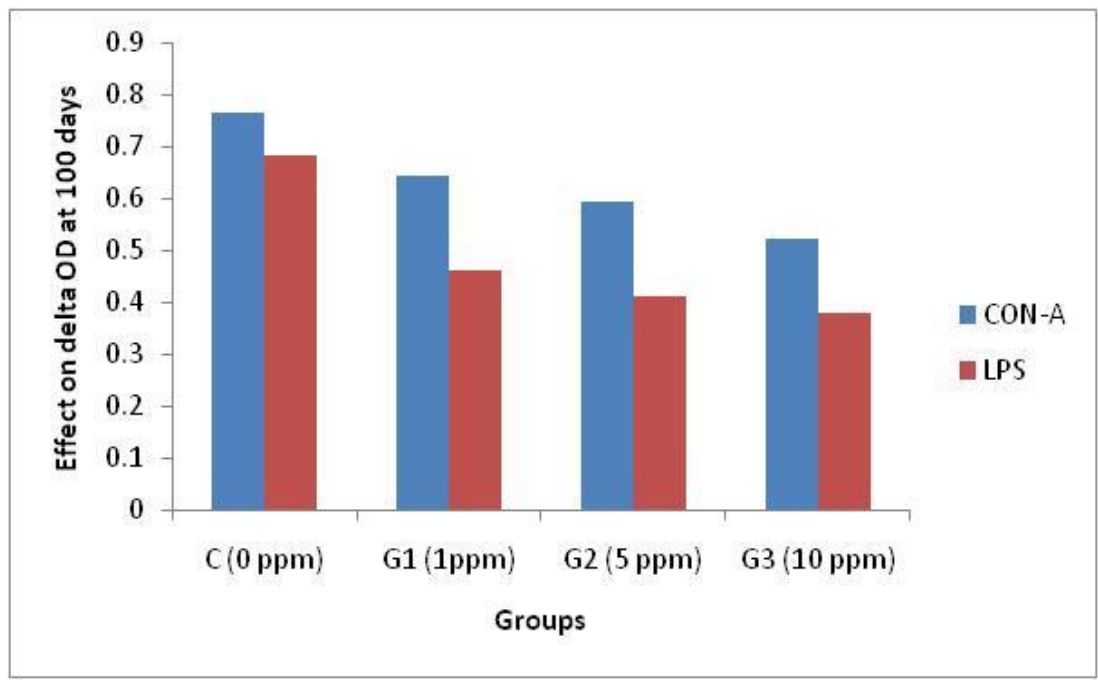

Graph 2:-

\section{Bibliography:-}

1. Bobe, A. M.-3. (1998). Kinetic and mechanism of abiotic degradation of fipronil. J. Agric. Food Chem. , 46 (28), 34-39.

2. Boyse, E., L.J., O., \& Chouroulinkov, I. (1964). Cytotoxic test for demonstration of mouse antibody. Methods in Medical Research (10), 39-47.

3. Chauhan, R. (1995). Textbook of Veterinary Clinical and Laboratory Diagnosis. (1 ed.). New Dehli: Jaypee Brothers Medical Publishers.

4. Chauhan, R., \& Singhal, L. (2006). Harmful effects of pesticides and their control through cowpathy. International Journal of Cow Science, 2 (1), 61-70.

5. Cole, L. M., Nicholson, R., \& Casida, J. E. (1993). Action of phenylpyrazole insecticide at the GABA-gated chloride channel. Pestic. Biochem. Physiol. , 46, 47-54.

6. Grant, D. B., Bloomquist, J. R., Ayad, H. H., \& Chalmers, A. (1990). A comparison of mammal and insect: GABA receptor chloride channel. Pest. Sci. , 30, 355-356.

7. Hainzl, D., Cole, L. M., \& Casida, J. E. (1998). Mechanism for selective toxicity of Fipronil insecticide and its sulphone metabolite and desulfinyl photoproduct. Chem. Res. Toxicol , 11, 1529-1535. 
8. Kamijima, M., \& Casida, J. E. (2000). Regional modification of [3H]ethynyl-bicyclo-orthobenzoate binding in mouse GABEA receptor by endosulphan, fipronil and avermectin B1a. Toxicol. Appl. Pharmacol. (160), 188194.

9. Kaushik, C., H.C., A., \& Pillai, M. (1991). Dry or aerial fallout of OCs insecticides residue in Delhi. Indian Environ. Pollution (71), 83-86.

10. Kumar, P. (2008). Indian poultry industry challenge and opportunity.

11. Oser, B. (1976). Hawk's Physiological Chemistry (14 ed.). New York: Mc Graw HillInc.

12. Rai-el-Balhaa, G., Pellerin, J., Bodin, G., \& Abdulla, A. (1987). Lymphoblastic transformation assay of sheep peripheral blood lymphocytes: a new rapid and easy to read technique. Comp. Immunol. Microbiol. Infes. Dis. (8), 311-318.

13. Ram, S., Shivankar, V., \& Patial, B. (1987). Evaluation of endosulfan in fodder cowpea. J. Entom. Res. (10), 40-43.

14. Rhone-Poulnec. (1996). 'Fipronil' worldwide technical bulletin. Lyon, France: Rhone-Poulnec, Agrochimie.

15. Snedecor, G., \& Cochran, W. (1989). Statistical Methods (8 ed.). Ames, Iowa State University Press.

16. (2009-2010). World poultry trends. In Watt Executive Guide.

17. Zhao, X., Yeh, J. Z., Salgado, V. L., \& Narahashi, T. (2005). Sulfone metabolite of fipronil blocks GABA- and glutamate activated chloride channels in mammalian and insect neurons. Toxicol Sci (84), 401- 402. 